\title{
Motherhood, evolutionary psychology and mirror neurons or: 'Grammar is politics by other means'
}

Article

Accepted Version

Lesnik-Oberstein, K. (2015) Motherhood, evolutionary psychology and mirror neurons or: 'Grammar is politics by other means'. Feminist Theory, 16 (2). pp. 171-187. ISSN 1741-2773 doi: https://doi.org/10.1177/1464700115586514 Available at https://centaur.reading.ac.uk/37231/

It is advisable to refer to the publisher's version if you intend to cite from the work. See Guidance on citing.

To link to this article DOI: http://dx.doi.org/10.1177/1464700115586514

Publisher: SAGE

All outputs in CentAUR are protected by Intellectual Property Rights law, including copyright law. Copyright and IPR is retained by the creators or other copyright holders. Terms and conditions for use of this material are defined in the End User Agreement.

www.reading.ac.uk/centaur

\section{CentAUR}


Central Archive at the University of Reading

Reading's research outputs online 
Motherhood, evolutionary psychology and mirror neurons or: 'Grammar is politics by other means'

The discovery of 'mirror neurons' in the middle $1990 \mathrm{~s}^{1}$ is part of the burgeoning field of neuroscientific research which seeks to explain how emotions and intersubjective communication operate at the level of brain-functioning. 'Mirror neurons' are neurons in the brain which are seen to activate whether a test-subject makes meaningful motions itself or whether it observes the same motions made by another. There remain, however, many complex issues around both the research methodologies employed in mirror neuron research (and neuroimaging more widely), and around the interpretations of the results obtained. More recently, critiques of mirror neuron research and its claims have also come to include specifically feminist perspectives, from Cordelia Fine's popular science account Delusions of Gender (2010), to Robyn Bluhm's thorough analysis of the ways neuroimaging results are interpreted on the basis of gender-stereotypes (2013) and Victoria Pitts-Taylor's discussion of the relevance of gendered theories of embodiment and intersubjectivity to mirror-neuron studies (2013). ${ }^{2}$ These feminist critiques differ amongst themselves in their approaches and interests and in turn refer to and engage with a range of much longer-standing debates within feminist critiques of science. It is the interest of this article to discuss further specific aspects of these references to and engagements with the longer history of feminist science-critiques. More specifically, I will consider here particular ideas about vision and seeing, and argue that these are underpinned by particular political positions.

Ideas of vision and seeing are fundamental to empirical science, as demonstrated, for instance, by Lorraine Daston and Peter Galison's magisterial account of the scientific history of objectivity (2007), where they examine in detail how over the course of the nineteenth century [...] the creation of a new epistemic virtue scientific objectivity $-[\ldots]$ drove scientists to rewrite and reimage the guides that divide 
nature in to its fundamental objects [...] Objectivity has not always defined science. Nor is objectivity the same as truth or certainty [...] to be objective is to aspire to knowledge that bears no trace of the knower (Daston and Galison, 2007: 16-17).

Feminist critiques of science have, of course, however, engaged thoroughly with how this supposedly 'objective' scientific gaze is nevertheless gendered and gendering, as argued famously from the work of Ludmilla Jordanova to that of Donna Haraway, Luce Irigaray and beyond. As Jordanova explains in Sexual Visions: Images of Gender in Science and Medicine between the Eighteenth and Twentieth Centuries,

It would be mistaken, however, to suppose that the goal is merely to add an additional consideration - gender - to the history of science and medicine. There are more general matters at stake. Over the last twenty years or so historians have become aware of the need to unpack the processes through which 'naturalization' takes place, whereby ideas, theories, experiences, languages, and so on, take on the quality of being 'natural', permitting the veiling of their customary, conventional and social characteristics.[...] It follows from what has been said that the biomedical sciences deploy, and are themselves, systems of representation (Jordanova, 1989: 5).

Donna Haraway writes, similarly, in the introduction to Simians, Cyborgs and Women. The Reinvention of Nature that the examination of the debates about 'scientific objectivity' in feminist theory argues for a transformation of the despised metaphors of organic and technological vision in order to foreground specific positioning, multiple mediation, partial perspective, and therefore a possible allegory for feminist scientific and political knowledge.[...t]he pronouns embedded in sentences about contestations for what may count as nature are themselves political tools, expressing hopes, fears and contradictory histories. Grammar is politics by other means (Haraway, 1991: 3). 
Pitts-Taylor, in her feminist theory-inspired discussion of mirror neurons, also refers to Haraway through Miriam Solomons' advocating of 'situated cognition, defined as the embeddedness of "representations of the world, learning, memory, planning, action and linguistic meaning in the body's environment, conceptual structures, tools and social arrangements"” (Pitts-Taylor, 2013: 858). Pitts-Taylor agrees with Solomons in understanding 'situated cognition as strongly resonant with feminist epistemologies, including Donna Haraway's notion of situated knowledges (Haraway 1991)'. However, the one particular aspect that Pitts-Taylor does not engage with in terms of Haraway's situatedness, is vision, because Pitts-Taylor agrees with Solomons in considering 'mirroring as situated, embodied perception'. Thus 'perception' itself remains in place as such and therefore is not examined further in Pitts-Taylor's discussion. Here, ideas will be examined of how scientific perception, in terms of vision and seeing specifically, determines how and why mirror-neuron research - a research both of and about 'seeing' takes place.

I have selected for close examination as a typical example Sarah Blaffer Hrdy's Mothers and Others. The Evolutionary Origins of Mutual Understanding (2009), specifically because it notably does not engage with the prior critiques of feminist theorists such as Haraway, despite their both being primatologists and despite the early debates between them (Hrdy also only minimally references Haraway, and does not engage with her critiques, in her previous Mother Nature. Maternal Instincts and How They Shape the Human Species (1999)). ${ }^{3}$ It is not my aim to critique Hrdy's theories of motherhood as such; critiques of motherhood as innate are widespread and longstanding in feminist theory and need not be rehearsed here. ${ }^{4}$ Instead, my interest here is why theories such as Hrdy's, which draw on the mirror neuron research and the wider claims mirror neuron research makes about evolutionary psychology, are so popular and widespread in current popular and academic 
discourses, both in the sciences and humanities, despite the long history of feminist critiques of science such as those of Jordanova and Haraway. I consider here, then, how and why a highly relevant history of feminist critiques of science has not been engaged with, or often even referred to, more widely in mirror neuron and mirror-neuron inspired evolutionary psychology. ${ }^{5}$ I therefore also engage to some extent with aspects of the ongoing debates about 'literary Darwinism' and its validity in literary studies which also refer to and rely on claims about mirror neurons. In these terms my discussion here has a two-fold aim: to examine the investments within the kinds of arguments of which Hrdy is but one example but through this to examine further what seems to be at stake more widely in maintaining this discourse.

Literary Darwinism relies on the idea that reading, and specifically the reading of literature, affects readers in particular and predictable ways; ways which have been shaped by evolution. ${ }^{6}$ Jonathan Kramnick explains:

Whereas the humanities believe in an infinitely plastic human nature, so the literary Darwinists claim, the biological and social sciences have discovered that the mind evolved many thousands of years ago in response to an environment we no longer live in. Their goal is to show how our evolved cognition can explain particular features of texts or facts about writing and reading (Kramnick, 2011: 316-17).

Key in Kramnick's account here is the term 'cognition', for both literary Darwinists and evolutionary psychologists more widely rely on cognition as being about feeling, thinking, learning, reading, and writing as transparent, knowable, stable, and universal processes. Leading literary Darwinist Brian Boyd, for instance, relies on an innate 'theory of mind' and mirror neurons as products of evolutionary adaptations which make humans 'mind readers': 'mirror neurons [...] fire when we see others act or express emotion as if we were making the same action and allow us through a kind of automatic inner imitation to 
understand their intentions and to attune ourselves to their feelings' (Boyd, 2010: 103-4). This innate mind-reading for literary Darwinists such as Boyd is what makes literature affect readers: '[a]s one mirror-neuron specialist remarks, in a phrase that could not be more relevant to story-telling, "when we (and apes) look at others, we find both them and ourselves"' (Boyd, 2010: 142, italics in original). The idea of 'affect' in literary studies relies on definitions of cognition and its visibility, predictability, and universality. Modernism scholar Daniela Caselli analysed this when she wrote in 2010 in this journal about 'affect theory' in literary studies that it:

emerges as a theoretical tool at a historical point when feminist theory, and theory in general, are focused on a process of self-criticism aimed, on the one hand, at questioning past methodological rigidities identified as the attachment to epistemology over ontology, the centrality of estrangement over affective identification, and the alleged dogma of constructivism, and, on the other, at engaging with areas of thought perceived as having remained for decades no entry zones, such as science (in particular neuroscience) and affect [...] In this way, art becomes the space of the encounter of affect as a surprising, apersonal, transhuman way of responding to matter around us [...] This space 'beyond' words [...] closely resembles [certain conceptions of a] preverbal space of infancy [...] the ineffable romantic joy of experiencing something one thought ineffably lost (Caselli, 2010: 243-4, italics in original).

Significantly in relation to Boyd's claims about how mirror neurons allow a finding both of 'others and ourselves', Caselli adds that ' $[\mathrm{t}]$ he elusive quality of affect [...is] essential to its promise of transcending notions of otherness, both within and without the self. Affect promises - creatively - to go beyond what theory - boringly - has been able to examine so far, and brings with this the allure of immediacy' (Caselli, 2010: 244). Caselli argues, then, that 'affect' is a political concept, which she sees as being deployed 'at a historical point' to 
assert a trans-historical, natural, spontaneous, and universal emotional dynamic. She places this as being in opposition to the retrospectively defined 'past methodological rigidities' of 'epistemology', 'estrangement', 'and the alleged dogma of constructivism.' Affect, Caselli analyses, invokes the natural, universal, and spontaneous in order to constitute " the new" in critical theory.' (Caselli, 2010: 241). ${ }^{7}$ Caselli's view of affect as relying on a 'transhuman way of responding' also underpins that ways Hrdy's evolutionary psychology of motherhood and Boyd's literary Darwinism assume that humans are innate 'mind-readers' and that this mind-reading operates to produce and shape determinate relationships between 'others' and 'selves', whether defined as a mother and its child, or a literary text and its reader.

\section{Mirror Neurons and Empathy; Self or Other?}

For Hrdy, in Mothers and Others, the defining characteristic of humans is 'hypersociality', which involves 'mindreading' and 'empathy'. Her core question in the book is how evolutionary pressures selected for hypersociality in humans but not in the closely related great apes, no matter how many similarities in principle there may be perceived to be between the two groups. It is the degree of sociality that to Hrdy forms the distinctive aspect of the modern human, in emotional terms. Central to Hrdy's definitions of intersubjective engagement - and to those whose theories she draws on for these definitions - are ideas of vision, looking and gazing, primarily in terms of eyes and faces, and foundational to this looking are the interactions between infants and mothers and 'allomothers' (Hrdy defines this as follows: 'An alloparent [...] refers to any group member other than the parents who helps them rear their young. Since it is often impossible to assign paternity, I often opt for "allomother," a term which might or might not include the father' (Hrdy, 2009: note on p. 22, italics in original).

One of the factors that Hrdy turns to in considering why according to her humans are more empathic and better at mindreading than great apes are mirror neurons: 
Neuroscientists quickly christened this new class of brain structures 'mirror neurons' because the same areas of the brain that would be activated by doing something are also activated just by watching someone else do the same thing. [...] Researchers hypothesize that mirror neurons allow creatures to vicariously experience what another individual is doing. By mentally going through the same motions, the mimic gains a better understanding of what the actor being copied is intending to do (Hrdy, 2009: 47-8).

These arguments implicitly rely on claims about what can be seen in neuroimages: a 'new class of brain structures' is only 'new' in so far as its difference from the 'old' relies on a difference not in fact in the brain areas which are seen to be 'the same areas', but in what is other to the brain areas, namely the 'new class of brain structures'. These 'structures' are what the neuroscientists' see as making the difference between 'doing something' and 'just [...] watching' but which they do not see as upheld in the 'brain areas'. In this sense, 'mirror neurons' do not exist, as they are seen as the 'same' neurons, regardless of the 'structural' difference between doing and watching. This perspective can see as a difference that which, according to itself, the brain area involved cannot see as a difference, thereby also excluding itself from being the perspective of that brain area, which cannot, after all, know the difference which the perspective claims to know. In these terms the neuroscientists making these observations do not consider how their own observing is itself by definition a product of that brain which they exempt themselves from: as Daston and Galison explain, this is a seeing that claims it can bear 'no trace of the knower' (Daston and Galison, 2007: 1617).

This causes fundamental difficulties around a claimed difference between 'seeing' and 'doing' which is nevertheless itself known through seeing: 'doing' is bounded within 
individuality and this limit can only be overcome to the extent that the mirror neurons 'allow' a 'vicarious [...] experience', which in turn implies it is not the 'doing' itself that is shared, but only the experience of that doing at one remove. Further, this 'vicarious [...] experience' is not in fact the 'doing' of another creature, but 'mentally going through the same motions'. In this sense, 'doing' is not shared between individuals by the mirror neurons, but mirror neurons 'allow' 'doing' as 'mental [...] motion'. Or, to put it otherwise, 'doing' is claimed to be seen as the 'same motions' but one is a non-mental motion which the mirror neurons 'allow' as a mental motion. In assigning to the mirror neurons the 'allowing' as a 'mirror', the non-mental and the mental are, however, therefore defined as separate and unshareable: the 'mirror' confirms the neurons' 'reflecting' as the production of the same motion yet as a difference through being merely ('just') mental. At the same time, this difference between doing and the mental reflection as motion is not known to the brain area or to its neurons which, we are told, do not distinguish between doing and watching. The difference, in this sense, is not there to be overcome by mirroring, except from and for the seeing which excludes itself from being that of the brain area involved.

To complicate matters even further, however, according to Hrdy's account of the mirror neurons, 'mentally going through the same motions' 'gains' for the 'mimic' (which, again, is not a 'mimic' except in this vision) 'a better understanding of what the actor being copied is intending to do' (Hrdy, 2009: 48), even though it is not known to be only 'mentally' for the brain areas or neurons, but only from the non-brain area perspective. The mimic who does not know it is mimicking cannot therefore 'gain' what it does not know it is doing, and indeed, in terms of the brain areas and neurons, is not doing. Nonetheless, this mimicking, under the terms of its unknown difference from itself, previously had an 'understanding' of what an 'actor being copied is intending to do'. There is here also a confusion of time in this account: the mirror neurons are firing regardless of whether there is a doing or a watching, 
and yet this firing already is known as a copying of something that is yet to take place as an 'intention'. Acting ('actor') therefore must precede a 'doing' (even though it is apparently not a 'doing' either) which is the certain outcome of a future 'intention', where the copying of the acting which is already known to be a copy 'gains' a 'better understanding' not of a 'doing', but only of that intention of a future 'doing'.

In short, neurons which do not know the difference between doing and watching, can through firing without regard for that difference lead to an increased understanding of an intention to do something, even though that something cannot itself be known to be a doing. In the end, all of this relies on a 'watching' nonetheless: for a doing is being watched as a doing in this narrative, even if only by the perspective which does not allow the firing neurons the ability to make this distinction. The perspective watches what it defines as the same neurons firing; watches, in other words, without knowing whether it is watching a 'doing' or a 'watching' while simultaneously claiming what a 'doing' and what a 'watching' are. The implications for the perspective are both that it has defined itself as not that brain area itself in terms of its knowledge of the difference between watching and doing, but also that it already always knows in advance that a mimicking (which does not know it is mimicking) is a prediction of a future doing. Moreover, this future doing in turn, inevitably in terms of this logic, is a watched doing, and not an experienced doing, anyway.

It may be important to stress that these problems are not just a result of Hrdy's specific narrative about them but trouble the very grounds of this research in its own right. For instance in one of the articles referenced by Hrdy (Jackson et al., 2005), the issue of perspective is also not considered, and this results in a definition of 'empathy' (the core concern of the article, as for Hrdy) which in turn relies on a perspective which has already assumed an ability to have a perfect knowledge of the pain levels and experiences of 'others', in turn relying on already assuming a knowledge of what constitutes the 'self' and what the 
'other': 'the activity in the anterior cingulate was strongly correlated with the participant's ratings of the others' pain, suggesting that the activity of this brain region is moderated according to subjects' reactivity to the pain of others' (Jackson et al., 2005: 771). In other words, a tautology is produced, as the participants' self-assessment is judged to agree with their own self assessment. This research, then, is a perfect example of pre-determining output by following pre-set assumptions; thus the researchers conclude, 'These findings offer one plausible explanation of how one is affected by another person's state and feelings' (Jackson et al., 2005: 777). The research relies on a perspective which can see both the 'one' and 'another person's' 'state and feelings' and can compare the two as such whilst apparently being itself implicated in neither.

Several scientific critiques of the mirror neuron and empathy research agree with my analysis here: Pierre Jacob and Marc Jeannerod, for instance, argue that ' $\mathrm{t}$ ] he motor properties of the mirror system are well designed for representing an agent's motor intention involved in an object-oriented action, not for representing an agent's social intention, let alone his communicative intention' (Jacob and Jeannerod, 2005: 24). John Cartwright, similarly, in considering mirror neurons and the origins of languages warns that the strong interpretation of mirror neurons supplying instant meaning to the observer faces one enormous problem. If it is suggested that mirror neurons only fire when the movement of an arm is directed towards some meaningful action (the grasping of an object) and replicate this meaning instantly inside the head of an observer, and not when confronted by movement alone, such as a hand moving towards a non-existent object, how does the mirror system 'know' that the former is meaningful? In essence, if meaning is supposedly presented instantly in the brain, how can the system decide to be selective before the action is complete? (Cartwright, 2008: 142) 
In other words, for Cartwright too, as in my analysis, the research methodology is flawed by the scientists assuming simply to be able to see in neuroimages what 'actions' and 'seeing' and the differences between them are. Moreover, both my analysis here and Cartwright's consider the issue of the time of seeing as a fundamental question for the research methodology, for when during the seeing can an action be seen as completed and when and how can it be seen as meaningful or intentional?

Another expert whose research in this area Hrdy refers to relies on the same problematic assumptions around mind-reading, seeing and doing, and intentionality. Hrdy heads her second chapter with a quote from Peter Hobson:

I sat gazing at a chimpanzee who sat on the other side of a fence, gazing at me. As a psychoanalyst, I have been taught to analyze the countertransference, which means that I try to formulate how this animal is making me feel. So I sat there and tried my very hardest to do that. I felt [...] something missing, I could not connect. I was reminded of the experience one sometimes get [sic] when relating to a child with autism [...] It was as if this chimp was not at home, mentally speaking (Hrdy, 2009: 33, citing Hobson, 2004: 270).

In terms of Hobson's own claims, the 'self' and 'other' and the interaction (or lack of it) between them are already assumed and determinative of Hobson's understanding of what this 'gazing' means: it is the chimp who Hobson already knows is 'gazing at me' but is nevertheless 'not at home, mentally speaking', and therefore is inducing Hobson himself to feel that there is 'something missing, I could not connect'. ${ }^{8}$ This 'something missing' is then linked to some cases of a remembered experience 'when relating to a child with autism', so that both 'autism' and being a chimp are about a lack of possibility of connection with an other due to a lack in themselves as chimp and autist. ${ }^{9}$ 
Hrdy warns that Hobson's encounter could have been different 'if Hobson actually [had] had a prior relationship with the chimpanzee, the eyes returning the gaze might well have seemed less blank'; but though it might seem initially that this critiques Hobson for a lack of understanding of the chimpanzee, Hrdy's following comment that '[c]ertainly there are circumstances when chimpanzees sense how someone else feels' (Hrdy, 2009: 34) places the responsibility for making connections (or failing to) squarely back with the chimp. But, in all these cases the self-defined adult, human perspective makes all of these claims about chimps' (and autistic children's) connections (or lack thereof), gazes, senses and mental states (or lack thereof) on their behalf. This raises the question: where is the chimp or the autistic child in any of this? I am not here pleading for somehow allowing the chimp or the autistic child their 'own voice', but am arguing that they can only be defined as 'other' by and for the adult human itself.

\section{Sharing and Giving Gifts; Socialization or Hardwiring?}

These difficulties, which result from overlooking (or not seeing as relevant) shifts in claims about the brain, mind, consciousness, seeing (perception) and vision (perspective), undermine the empathy and mindreading which rely on those claims, and therefore also the arguments about (allo)-mothers and infants which in turn rely fundamentally on empathy and mindreading. For Hrdy, the 'urge to share is hardwired', even if 'custom, language and personal experiences shape the specifics' (Hrdy, 2009: 25), where the 'specifics' of 'custom, language and personal experience' do not obscure for Hrdy the fact that this is all the same 'sharing'. This confidence of Hrdy's in the recognition of sharing extends to a confidence in the recognition of a 'gift' and 'giving', which is in turn as fundamental to the 'empathy and 'mindreading' which underpin her definition of the high degree of interactive engagement of (allo-)mothers and infants. The gift and giving work to demonstrate in Hrdy's argument how much more humans are 'eager to connect with others' (Hrdy, 2009: 23) than even the great 
apes. Although the claim to 'hardwiring' is essential to Hrdy's evolutionary argument, she is surprisingly equivocal in both her ongoing claims in the text about how 'hardwired' they are, as well as, again, surprisingly equivocal about how sharing and gift-giving are to be defined and recognised.

For instance, directly after the claim that 'a human child is born eager to connect with others' the following claim occurs that 'before Ju/'hoansi children are a year old and able to talk, they are already socialized to share with their mother and other people as well' and that 'the first words a child learns are na ("Give it to me") and $i$ ("Here, take this")' (Hrdy, 2009: 23). The human child here is born knowing that it is not connected to 'others' and 'eager' to address this deficit, therefore by implication already knowing about connection itself. Yet in the subsequent comments sharing is something the child needs to be 'socialized' to do, which would imply that this is not an originary feature, but a trait which is produced by the interactions with others. In this sense, 'connection' here is different from 'sharing', but perhaps can be taken as a prerequisite willingness to undergo 'socialization' resulting from the innate wish to connect. In any case, the socialization to sharing here stands in direct contradiction to the prior claim that 'the urge to share' itself is 'hardwired'. Similarly, 'among the first words' are 'learn[ed]', and the first words enlisted as examples of this socialization are instructions to 'Give it to me' and 'Here, take this', where the question is how these are to be understood as spontaneous acts of sharing and giving on the part of the child, underscoring the contradiction between the claims to 'hardwiring' and 'socialization'. These equivocations (advertent or inadvertent) continue throughout: in a subsequent anecdote relayed from anthropologist Polly Wiessner, 'an old woman' places her grandchild's ostrich shell beads 'in the child's hand to present (however grudgingly) to a relative. After the lesson of giving was accomplished [...] This routine was repeated until, by about age nine, children themselves initiated giving' (Hrdy, 2009: 23). The child has to be instructed to give the beads 
and how to give the beads to another, doing so 'grudgingly', and the giving again has to be taught as a 'lesson' and through a 'routine'. It is hard to see how this can be taken, even in its own terms, as a description of a 'spontaneous' and 'reciprocal' sharing which Hrdy claims is in contrast to the "nonhuman apes" lack of such activity. At the very least it raises for me the question how and why Hrdy is so sure these kinds of anecdotes necessarily support the assertion that sharing and giving are hardwired in humans to a degree they are not in nonhuman apes.

\section{Further on Sharing and Giving Gifts: Altruism or Investment?}

Hrdy's further examples, invoked to continue to support these differences between apes and humans, continue throughout to equivocate not only about what demonstrates 'hardwiring', but also over what constitutes sharing and giving: an 'alpha male chimpanzee grasping the carcass of a monkey he just killed may allow a sexually receptive female or close male associate to rip off a piece, but this is more like "tolerated theft" than a real gift' (Hrdy, 2009: 23). The notion of a 'real gift' is at stake here, where 'tolerated theft' relies on the ideas that this is an 'alpha male' who can 'allow' only specifically privileged individuals from whom he may expect future reciprocal favours (sexual favours from the female and support from the male), to take by force ('rip') for themselves a small part of the meat. This is contrasted with 'real gifts' in terms of 'humans' who 'routinely offer preferred foods to others - the best hospitality we can possibly provide' (Hrdy, 2009: 23). This version of the 'real gift' neither coincides with Hrdy's anecdotes of the 'socialization' in to giving, nor is it consistent with her further accounts of the anthropology of gift-giving where she states, for instance, that the 'point is not merely to share but to establish and maintain social networks' (Hrdy, 2009: 12).

This equivocation between sharing, and gift-giving as spontaneous, voluntary and altruistic, and sharing and gift-giving as canny investments in social networks can be tracked throughout Hrdy's arguments and raises fundamental problems for her assertions about, and 
definitions of, hardwiring versus socialization. Furthermore, this very division of voluntary, spontaneous gift-giving versus a minimal, begrudging sharing tolerated only in the face of the prospect of a direct return is not a necessary and natural division, but itself relies on specific assumptions. Donna Haraway writes that 'Hrdy [...] is perhaps [...] a guide to the cultural logic of late capitalism' (Haraway, 1991: 350), and in line with this I read an inevitable regression in Hrdy's definitions back to that very competitiveness which she hoped to overturn in Mothers and Others in favour of an evolutionary account of cooperation. In that classic twist of capitalist logic, as Haraway puts it, even Hrdy's gift-giving turns out after all to be a self-interested investment, albeit with a possibly longer-term, deferred return; as Hrdy writes, 'The people you treat generously this year, with the loan of a tool or gift of food, are the same people you depend on next year when your waterholes dry up or game in your home range disappears' (Hrdy, 2009:6).

Hrdy, characteristically, also takes Marcel Mauss's classic Essai sur le Don (The Gift) to be arguing that the "point is not merely to share but to establish and maintain social networks' (Hrdy, 2009: 12, referring to Mauss, 1990 [1950]), while Mary Douglas, in her 'Foreword. No free gifts' to the English translation of The Gift argues that 'The Essay on the Gift was a part of an organized onslaught on contemporary political theory, a plank in the platform against utilitarianism', highlighting how she reads Mauss's text 'in a tradition strongly opposed to English liberal thought' (Douglas, 1990: viii). For Douglas, then, unlike for Hrdy's illustrative anecdotes, Mauss's text is not about liberal, self-interested, investment agents, acting as individual units (even in terms of cooperation), but instead 'rightly remarks that the concept of interest is itself modern' (Douglas, 1990: xiv) and establishes as axiomatic that a field report would be below standard unless a complete account could be given of all transfers, that is, of all dues, gifts, fines, inheritances and successions, tributes, fees and payments; when this information is in place one 
also knows who gets left at the end of the day without honour or citizenship and who benefits from the cumulative transfers. With such a chart in hand the interpreter might be capable of sensing the meanings of ballads, calypsos, dirges, and litanies; without it one guess will do as well as any other (Douglas, 1990: xiixiii).

The equivocation in Hrdy's arguments can then be taken in this sense as not an arbitrary equivocation but as born out of her specifically liberal, capitalist conceptions of the liberal individual and its 'gifts', 'giving' and 'sharing'. In other words, what has taken place is a shift from Douglas' reading of Mauss's argument as about systems of meaning to Hrdy's reading of it as the registration of individuals' expressions of innate features.

\section{Mothers and Mothering}

The difficulties traced above reverberate continuously throughout the ideas of mothers and mothering in the text. For instance, Hrdy asserts that '[c]himpanzee, orang-utan, and gorilla mothers are more single-mindedly devoted than human mothers are, and for much longer periods.[...] Yet apes do not teach or learn from others nearly so readily as humans do, and typically not at all.' Hrdy adds the question '[s]o why haven't chimpanzees been selected to develop the same sort of mind-reading skills that pay off in more efficient learning among humans?' (Hrdy, 2009: 43). These assertions and questions rest on assumptions about what 'learning and teaching' and 'mindreading' are, and these ideas in turn rest on the assumption that such processes do in fact take place in humans. We have already seen that the mirror neuron theories do not offer an unproblematic basis for this idea of mindreading and, similarly, Hrdy's view of great ape mothering apparently excludes her perceptions of their 'single-mindedly devoted' care from both 'mindreading' and from 'more efficient learning'. Or, as Hrdy further elaborates, 'If mind-reading human mothers respond more flexibly to infant needs and are better equipped to rear and tutor offspring why haven't other apes spent 
6 million years evolving and refining their intersubjective aptitudes?' (Hrdy, 2009: 43), so, again, 'single-minded devotion' is neither flexible nor a refinement of 'intersubjective aptitudes'.

\section{Winnicott, the Baby and the (Allo)Mother. Again: Self or Other?}

In terms of the great apes whose devotion is not mindreading, Hrdy's reading of Donald Winnicott (as with her reading of Mauss) is instructive: Hrdy mentions that 'There is no such thing as a baby', the child psychiatrist David [sic] Winnicott liked to say. 'There is a baby and someone.' The someone he had in mind was the mother (Hrdy, 2009: 111).

If I return to Winnicott's own text, I do so neither to 'correct' Hrdy's reading, nor to suggest that my alternate reading of Winnicott offers a 'right' version of the baby, but to highlight how Hrdy's baby relies on the same assumptions about autonomous, individual agents as do her adult sharers and gift-givers. For Winnicott makes his comment 'There is no such thing as an infant' (Winnicott, 1976: 39, note 1) in the context precisely of his psychoanalytical consideration that

The paradox is that what is good and bad in the infant's environment is not in fact a projection, but in spite of this it is necessary, if the individual infant is to develop healthily, that everything shall seem to him to be a projection. [...] and to this observation we can add that the recognition of a true 'not-me' is a matter of the intellect; it belongs to extreme sophistication and to the maturity of the individual (Winnicott, 1976: 38).

As with Hobson's chimp and autistic child who were invoked by Hrdy as making Hobson feel that they were 'mentally not at home' but assumed thereby as separate, autonomous entities responsible for communicating to him their 'not at home'-ness, Hrdy calls on Winnicott's remark to support her view that the baby is always already in 
existence, and is only 'not there' in so far as it is not, and could not survive, alone, for there is the 'and someone'. As Hrdy writes, 'recent research in infant psychology indicates that little humans are casting their nets more broadly to encompass others as well as mothers, evaluating their intentions and learning from their actions'(Hrdy, 2009: 111). For Hrdy, then, the baby is capable of this 'evaluating' and 'learning from' the 'intentions' and 'actions' which are 'their[s]'. In other words, unlike Winnicott's baby for whom 'everything shall seem [...] to be a projection', Hrdy's baby is unquestionably aware of itself as a separate entity with its own intentions and actions in relation to known and knowable 'others' who have their own intentions and actions which it can evaluate. 'Mindreading', then, for both adults (including (m)others) and children, relies on an assumed, innate separation of individual agents which must be overcome by a correct understanding of each other. As Pierre Jacob and Marc Jeannerod assert even as they critique aspects of mirror neuron theory, '[o]ne way to question the motor theory of social cognition would be to challenge it to account for the human capacity to read one's own mind or to ascribe false beliefs to others - something that healthy human adults do all the time without effort' (Jacob and Jeannerod, 2005: 21). As with Jacob and Jeannerod, for Hrdy these things are indeed something that 'healthy adults do all the time without effort' and this forms the grounding assumption for her readings and arguments in every case.

As Hrdy writes:

At some point in the emergence of the genus Homo, however, mothers became more trusting, handing even quite young infants over to others to temporarily hold and carry. [...] A baby thus had far more incentive to monitor his mother's whereabouts and to maintain visual and vocal contact with her, as well as far more motivation to pay attention to her state of mind and also to the willingness 
of others who might be available to care for him [...] I propose that such separations $[\ldots]$ caused little apes, already endowed with considerable gifts for reading (and even imitating) the facial expressions of others and with the neural equipment for rudimentary mind reading, to devote even more time and attention to interpreting the intentions of others, an activity which in turn would affect the organization of their neural systems (Hrdy, 2009: 114-15).

A primary 'separation' is here therefore already in place from the start and is extended through further physical separation. Both the primary and enhanced separation must, however, be overcome, and it is this that 'empathy', 'mindreading', 'connection' and 'intention' are invoked to negotiate. Finally, it is the responsibility of this baby ready from birth to undertake these tasks to ensure its own survival in these terms that is the evolutionary driver in Hrdy's theory of mothers, others and babies: 'I [Hrdy] am arguing that the most plausible way to explain this difference between humans and other apes is to take into account the vast stretch of time [...] during which babies who were better at gauging the intentions of others and engaging them were also better at eliciting care, and hence more likely to survive into adulthood and reproduce' (Hrdy, 2009: 117).

\section{Conclusion: What Counts as a Legitimate Scientific Narrative?}

There are many ways in which, as Peter Ellison put it in his review of Mothers and Others, 'it is useful, when presented with any $\mathrm{T}(\mathrm{A}) \mathrm{E}$ [a theory of (almost) everything], to imagine the logical alternatives and to think them through' (Ellison, 2009: 447), and he proposes some of his own. However, this article has not sought to pursue such an imagining. Instead, it has sought to produce readings of Hrdy's text, and several of the texts she invokes in turn, which do not rely on certain given assumptions about science and scientific narrative and how they must be written and read. Instead, taking prior arguments from the history of feminist 
critiques of science as a starting point, it has re-traced, through close readings of Hrdy, Haraway's critique in Primate Visions (1989) of a vision of 'science' which sets it in opposition to 'fiction', and a 'nature' in opposition to 'culture' (amongst other oppositions). These oppositions rest on the same ideas of self-constituted, natural entities which can always already be seen to be as separate as Hrdy's adult and baby mindreaders and empathizers and as the mirror neuron systems they in turn rely on also rest on such oppositions. My interest in pursuing this reading has come from my own continued puzzlement over how, with the ongoing academic and mass-media popularity of evolutionary psychology and biology, longstanding and fundamental critiques such as Haraway's of Hrdy seem to me to be considered as unnecessary to engage with, even in order to refute them, or to be simply unknown. In my analyses here, I read this non-engagement with, or forgetting of, critiques such as Haraway's as a symptom of the current unquestioning acceptance of the politics of the liberal, autonomous individual, whose mindreading and empathy redeem them from the threat of a capitalist isolation, selfishness and pure greed. As Hrdy writes:

From a tender age and without special training, modern humans identify with the plights of others and, without being asked, volunteer to help and share, even with strangers. [...] Think back to the tsunami in Indonesia or to hurricane Katrina. Confronted with images of the victims, donor after donor offered the same reason for giving: Helping was the only thing that made them feel better. [...] This ability to identify with others and vicariously experience their suffering is not simply learned: It is part of us (Hrdy, 2009: 4).

Clearly, it would be churlish to question such a beautiful story; but more than that, were anyone to do so then their questioning of the 'us' itself defines the questioner for those who believe in such theories as not 'us' but, therefore, as a 'stranger' or 'other'. This stranger or other is, however, now one who by implication can neither be identified with nor whose 
suffering can be vicariously experienced. This returns us to the old conundrum that when and where feminism - or any politics of liberation - comes to demand an unquestioning allegiance to an unquestionable truth, it automatically comes to rest on a political dynamic of exclusion and hierarchy in turn; and never more so than when it insists that it has mastered that conundrum.

\section{Notes}

1. See: V. Gallese et al. (1996) and V. Gallese and A. Goldman (1998). The ongoing persistence of the investment in 'mirror-neurons' and their implications is reflected, for instance, in the 2014 publication of a special issue of the Philosophical Transactions of the Royal Society on 'Mirror neurons', compiled and edited by P. Ferrari and G. Rizzolatti.

2. See for an excellent, wider critique of the mirror neuron research which is not specifically, however, concerned with gender or vision in the sense I am considering here, R. Leys (2012), and for a recent, scientific critique of the statistical claims of neuroscientific research: K. Button et al. (2013). Leys is puzzled at the ongoing popularity of mirror neuron theories and their resistance to both scientific and theoretical critiques, but does not make this question the focus of her article, concluding that 'Simply put, the network of presuppositions and methods associated with the Basic Emotions View is too attractive and the laboratory methods too convenient to be given up' (Leys, 2012: 6).

3. See for Haraway's original critiques of Hrdy's work both Haraway (1989) and (1991). 4. C. Fine (2010) also argues why several of the claims about gender and parenting in Hrdy's book are problematic. Several of the wide-spread criticisms of Fine's arguments do not address the issues I am analysing here.

5. For further critiques of evolutionary psychology from a specifically humanist perspective see: R. Tallis (2011); D. S. Wiesberg et al. (2008); J. Corrigall and H. Wilkinson (2003); M. Bullowa (ed.) (1979); M. Posner (ed.) (2004); M. Wolf (2007). However, it is the question of 
affect which underpins the divergence of the arguments in this essay from these humanist positions, as discussed through D. Caselli’s arguments quoted here; see also K. LesnikOberstein (1998).

6. There have recently been a number of heated debates around 'literary Darwinism' and its validity in essays such as those by T. Karshan (2009) and J. Kramnick (2011).

7. For an analysis of how intentionality is at the core of ideas of 'affect' as well as a wider critique of affect from a different perspective to D. Caselli's see R. Leys (2011).

8.It is relevant that this is consistent with my having a different understanding of 'countertransference' to Hobson (at least in this quote): whilst for Hobson countertransference seems to be having a conscious feeling induced in oneself by another which then turns out when 'formulate[d]' to be a revelation of the perception of the true state of that other, I take countertransference to be unconscious on the part of the analyst and in relation to the transference of the patient, where neither the transference nor the countertransference themselves are necessarily known as 'belonging' to the analyst or the patient. As J. Laplanche and J. B. Pontalis define counter-transference in their classic The Language of Psychoanalysis: 'The whole of the analyst's unconscious reactions to the individual analysand - especially to the analysand's own transference.[...] transference and counter-transference are no longer seen as processes specific to the analyst and the analysand respectively [...] we have to ascertain the part of transference and the part of countertransference in each of the two people present' (Laplanche and Pontalis, 1973: 92-3).

For a critique of mirror neuron claims also specifically in relation to countertransference which shares some of my concerns see: J. M. Vivona (2009). 9. For an extensive analysis of how 'autism' is constructed as a lack which nevertheless knows about its own lack, see H. Ainslie (2011). 


\section{References}

Ainslie, H. (2011) 'Perspectives and community: Constructions of autism and childhood'. In

K. Lesnik-Oberstein (ed.) Children in Culture, Revisited. Further Approaches to Childhood. Houndmills: Palgrave, 90-107.

Bluhm, R. (2013) 'Self-Fulfilling Prophecies: The Influence of Gender Stereotypes on Functional Neuroimaging Research on Emotion'. Hypatia. 28(4): 870-886.

Boyd, B. (2010) On the Origin of Stories: Evolution, Cognition and Fiction. Cambridge. Mass.: The Belknap Press of Harvard University Press.

Bullowa, M. (ed.) (1979) Before Speech: The Beginning of Interpersonal Communication. Cambridge: Cambridge University Press.

Button, K., Ioannidis, J. P. A., Mokrysz, C., Nosek, B. A., Flint, J., Robinson E. S. J. and Munafò, M. R. (2013) 'Power Failure: Why Small Sample Size Undermines the Reliability of Neuroscience', Nature Reviews Neuroscience, 14: 365-376, doi:10.1038/nrn3475.

Cartwright, J. (2008) Evolution and Human Behaviour. Darwinian Perspectives on Human Nature. Houndmills: Palgrave Macmillan, second edition.

Caselli, D. (2010). 'Kindergarten theory: Childhood, affect, critical thought'. Feminist Theory. Special issue on childhood. Eds. E. Burman and J. Stacey, 11(3): 241-54.

Corrigall, J. and Wilkinson, H. (2003) Revolutionary Connections: Psychotherapy and Neuroscience. London: Karnac.

Daston, L. and Galison, P. (2007) Objectivity. New York: Zone Books.

Douglas, M. (1990) 'Foreword. No free gifts'. In: Mauss, M. (1990 [1050]) The Gift. The Form and Reason for Exchange in Archaic Societies. Trans. W. D. Halls. London: Routledge, 1990 [1950], vii-xviii. 
Ellison, P. (2009) 'A growing thought. A review of Sarah Blaffer Hrdy, Mothers and Others: The Evolutionary Origins of Mutual Understanding'. Evolutionary Psychology, 7(3): 442448.

Ferrari, P. and G. Rizzolatti (eds) (2014). 'Mirror neurons: fundamental discoveries, theoretical perspectives and clinical implications'. Special issue of the Philosophical Transactions of the Royal Society. 369 (1644).

Fine, C. (2010) Delusions of Gender. The Real Science Behind Sex Differences. London: Icon Books.

Gallese, V., Fadiga, L., Fogassi, L. and Rizzolatti, G. (1996) 'Action Recognition in the Premotor Cortex'. Brain. 119: 593-609.

Gallese, V., and Goldman, A. (1998) 'Mirror neurons and the simulation theory of mindreading', Trends in Cognitive Sciences. 12(12): 493-501.

Haraway. D. J. (1989). 'Sarah Blaffer Hrdy: Investment strategies for the evolving portfolio of primate females'. In D. J. Haraway. Primate Visions. Gender, Race and Nature in the World of Modern Science. London and New York: Routledge, 349-368.

Haraway, D. J. (1991) Simians, Cyborgs and Women. The Reinvention of Nature. New York, NY: Routledge.

Hobson, P. (2004) The Cradle of Thought: Exploring the Origins of Thinking. Oxford: Oxford University Press.

Hrdy, S. B. (2009) Mothers and Others. The Evolutionary Origins of Mutual Understanding. Cambridge, Mass.: The Belknap Press of Harvard University Press.

Hrdy, S. B. (1999) Mother Nature. Maternal Instincts and How They Shape the Human Species. New York, NY: Ballantine.

Jackson, P. L., Meltzoff, A. N., Decety, J. (2005) 'How do we perceive the pain of others? A window into the neural processes involved in empathy'. NeuroImage 24: 771-9. 
Jacob, P., Jeannerod, M. (2005) 'The motor theory of social cognition: A critique'. TRENDS in Cognitive Sciences 9(1): 21-5.

Jordanova, L. (1989) Sexual Visions: Images of Gender in Science and Medicine between the Eighteenth and Twentieth Centuries. Hemel Hempstead: Harvester/Wheatsheaf, and Madison: University of Wisconsin Press.

Karshan, T (2009) ‘Evolutionary criticism’. Essays in Criticism. 59(4): 287-301.

Kramnick, J. (2011) ‘Against literary Darwinism’. Critical Inquiry 37(2): 315-47.

Laplanche, J., Pontalis J. B. (1973) The Language of Psychoanalysis. Trans. D. NicholsonSmith. London: The Hogarth Press and the Institute of Psychoanalysis.

Leys, R. (2011) 'The turn to affect: A critique.' Critical Inquiry. 37: 434-72.

Leys, R. (2012) “"Both of us disgusted in my insula": Mirror neuron theory and emotional empathy'. Nonsite.org. 5: 1-25. Accessed on 11/04/2013 at: http://nonsite.org/article/“bothof-us-disgusted-in-my-insula"-mirror-neuron-theory-and-emotional-empathy

Mauss, M. (1990 [1950]) The Gift. The Form and Reason for Exchange in Archaic Societies. Trans. W. D. Halls. London: Routledge.

Pitts-Taylor, V. (2013) 'I Feel Your Pain: Embodied Knowledges and Situated Neurons'. Hypatia. 28(4): 852-69.

Posner, M. (ed.) (2004) Cognitive Neuroscience of Attention. New York, The Guilford Press. Small, M. (1995, new edition) Female Choices. Sexual Behaviour of Female Primates. Ithaca, NY: Cornell University Press.

Solomon, M. (2007), ‘Situated cognition'. In Philosophy of Psychology and Cognitive Science, ed. Paul Thagard. New York: Elsevier.

Tallis, R. (2011). Aping Mankind: Neuromania, Darwinitis and the Misrepresentation of Humanity. Durham: Acumen Publishing. 
Vivona, J. M. (2009) 'Leaping from brain to mind: A critique of mirror neuron explanations of countertransference'. The Journal of the American Psychoanalytical Association 57(3): $525-50$.

Wiesberg, D. S. et al. (2008) 'The seductive allure of neuroscience explanations'. Journal of Cognitive Neuroscience. 20(3): 470-477.

Winnicott, D. W. (1976) 'The theory of the parent-infant relationship'. In Winnicott, D. W., The Maturational Processes and the Facilitating Environment. Studies in the Theory of Emotional Development. London: The Hogarth Press and The Institute of Psychoanalysis, 3756.

Wolf, M. (2007) Proust and the Squid: The Story and Science of the Reading Brain. New York: HarperCollins. 